Cuad. Invest. Filol., 46 (2019), 77-102. http://doi.org/10.18172/cif.3890

\title{
PROCEDIMIENTOS DE IMPERSONALIZACIÓN EN LA CIUDAD DE SEVILLA: EL CASO DEL PRONOMBRE UNO ${ }^{1}$
}

\author{
Doina Repede \\ Universidad de Sevilla \\ doinarepede@gmail.com \\ Marta León-Castro Gómez \\ Universidad de Sevilla \\ mleoncastro@us.es
}

\begin{abstract}
RESUMEN: El objetivo de este artículo consiste en describir el uso del pronombre uno como mecanismo de impersonalización en la comunidad urbana de Sevilla, en concreto, en una muestra de habla compuesta por 72 entrevistas del sociolecto alto, medio y bajo, pertenecientes al Corpus PRESEEA-Sevilla. Esta forma pronominal adquiere en el contexto diferentes funciones semánticas que van desde la generalización (inclusiva o exclusiva) hasta el encubrimiento pragmático del hablante, cuya finalidad consiste en proteger su imagen, buscar acuerdo social o criticar. Además, estos grados de impersonalidad están relacionados con factores sintácticos (la clase semántica del verbo), pragmáticos (temática de la conversación, secuencia discursiva), estilísticos (la relación entre los participantes en la interacción) $y$, en menor medida, con los criterios sociales (edad, sexo o nivel de instrucción).

PALABRAS CLAVE: uno, impersonalización, generalización, encubrimiento pragmático, sociolingüística, PRESEEA-SE.
\end{abstract}

\section{IMPERSONALIZATION PROCEDURES IN THE CITY OF SEVILLE: A STUDY ON THE PRONOUN "ONESELF"}

ABSTRACT: The aim of this study is to describe the use of "oneself" as an impersonalization strategy in the city of Seville, specifically, in a sample of 72 oral interviews of high, medium and low sociolect, taken from the Corpus PRESEEA-

1. Este trabajo forma parte del proyecto Patrones Sociolingüisticos del Español de Sevilla (PASOS-SE). Proyecto de Excelencia convocatoria 2015. Ref. FFI2015- 61871-C5-3-P. Financiado por el Ministerio de Economía y Competitividad de España y Fondo Europeo de Desarrollo Regional (MINECO/FEDER, UE). 
Seville. This pronoun presents in the context different semantic values which go from generalization (both inclusive and exclusive) to pragmatic concealment of the speaker, with the purpose of protecting the latter's image, criticizing or searching for approval and social acceptation. Furthermore, these different shapes of impersonalization are related to syntactic factors (verb semantic class), pragmatic (theme of the conversation, discourse sequence), stylistic (the relationship between the participants joining the interaction) and, to a lesser extent, with the social aspects (gender, age or educational level).

KEYWORDS: oneself, impersonalization, generalization, pragmatic concealment, Sociolinguistics, PRESEEA-SE.

\title{
PROCÉDURES D'IMPERSONNALISATION DANS LA VILLE DE SÉVILLE : UNE ÉTUDE SUR LE PRONOM « SOI-MÊME»
}

\begin{abstract}
RÉSUMÉ : Cette étude se propose de rendre compte de l'emploi du pronom indéfini "soi-même » comme mécanisme d'impersonnalisation dans la ville de Séville. Elle s'appuie sur des entretiens semi-directifs avec 72 sociolectes ayant un niveau éducatif haut, moyenet et bas, et qui font partie du corpus oral PRESEEA-Séville. Cette forme pronominale présente dans le contexte des fonctions sémantiques différentes qui vont de la généralisation (inclusive ou exclusive) á la dissimulation pragmatique du locuteur dont le but consiste à protéger son image, à acquérir l'accord ou à critiquer. En outre, ces degrés d'indétermination sont associés aux facteurs syntactiques (la clase sémantique du verbe), pragmatiques (la thématique de la conversation, la séquence discursive), stylistiques (la relation entre les deux intervenants dans l'interaction) et, dans une moindre mesure, aux critères sociaux (l'âge, le genre ou le niveau éducatif).

MOTS CLÉS : soi-même, impersonnalisation, généralisation, dissimulation pragmatique, Sociolinguistique, PRESEEA-SE.
\end{abstract}

Recibido: 03/12/2018. Aceptado: 03/04/2019

\section{Introducción}

Entre las acepciones que ofrece el DLE (2014) sobre uno como pronombre indefinido se encuentran la que hace referencia a una persona (en ejemplos como 
"salía uno jugando a la pelota y casi le pegó a un rival en la cabeza / y otro $<$ vacilación/> otra película / uno con unos troncos / rodando unos troncos por un campo / parece que se llevaba los troncos a la cabeza" (SEVI_M31_022) ${ }^{2}$, uno se refiere en ambos casos a un tipo concreto, un personaje de las películas que está contando), al propio hablante o a una persona indeterminada. Son las dos últimas las que nos interesan en este trabajo, pues representan las dos lecturas que puede tener uno como mecanismo de impersonalización: por un lado, un recurso generalizador para emitir una afirmación de validez más o menos universal y, por otro, una estrategia para ocultar la identidad del hablante con fines distintos en el discurso.

No obstante, hemos de precisar que ambas interpretaciones, lejos de ser incompatibles, están interrelacionadas, de modo que a menudo el hablante parte de una vivencia propia o de otro individuo para hacerla extensiva a otras personas y al revés: generaliza para reforzar una experiencia concreta. Por tanto, hemos de situar el fenómeno en un continuum con dos polos extremos (ocultación y generalización) a los cuales se aproxima en cada caso condicionado por una serie de factores contextuales ${ }^{3}$. "Se trata pues de un asunto del que podemos ocuparnos en términos graduables, ya que adquieren valores diversos según el contexto lingüístico en el que se encuentran inmersos y atendiendo igualmente a la influencia que reciben de distintos factores extralingüísticos" (León-Castro 2012: 28).

Son muchos los autores que han tratado este asunto desde enfoques diversos y empleando en sus trabajos diferentes terminologías. Así pues, Haverkate (1994: 131) utiliza el término desfocalización, que define como "una táctica de distanciamiento con la que el hablante minimiza su propio papel o el del oyente en el discurso". Briz Gómez (1998: 154-156) describe un "tipo de atenuación pragmática que afecta directamente al papel de los participantes de la enunciación" y que tiene dos manifestaciones claras. Por un lado, se refiere a una atenuación por impersonalización del yo: se minimiza el papel del hablante mediante distintos recursos como el indefinido uno/una o el tú impersonalizado para salvaguardar su imagen respecto al interlocutor. Por otro, alude a la despersonalización del tú que se caracteriza por ser un recurso "especialmente relevante en el coloquio con el que el hablante pretende por ejemplo mitigar un reproche a su interlocutor"

2. Los ejemplos deben leerse de la siguiente forma: i) $\mathrm{SEVI}=$ Sevilla; ii) sexo: $\mathrm{H}=$ hombre, $\mathrm{M}=$ mujer; iii) edad: $1=20$ a 34 años, $2=35$ a 55 años, $3=55$ años en adelante; iv) nivel de educación: $1=$ instrucción primaria; v) identificación del hablante dentro del corpus: 001, 002, 003, etc.

3. Fuentes y Alcaide (2002: 141) hablan de un gratatum donde situar las estructuras impersonalizadoras en función de la mayor o menor indeterminación que expresan. 
(Mancera Rueda 2009: 80). En este caso, utiliza estructuras del tipo hay que + infinitivo con las que se intenta proteger la imagen del receptor.

Alcaide Lara (2001: 291-292), entre otros, habla de impersonalidad, la cual "está ligada a la indeterminación o no especificación del sujeto agente de la acción por diversos motivos, pero no necesariamente a la imposibilidad de expresarlo". En la misma línea terminológica, Gómez Torrego (1994: 9-10) diferencia entre oraciones impersonales desde el punto de vista semántico y sintáctico. Las primeras ocultan el agente o actor de la acción verbal ya sea por generalización, indeterminación o encubrimiento pragmático. Con respecto a las impersonales desde el punto de vista sintáctico, existe una ausencia del sujeto léxico-sintáctico (independientemente de si se omite el agente de la acción verbal).

Asimismo, para Muñiz Cachón (1998: 66) "una oración es impersonal cuando resulta imposible la actualización de un sujeto léxico" o bien cuando, pudiendo tenerlo, "la oración adquiere carácter genérico o indeterminado por no apuntar a una persona concreta del discurso, y además, la referencia del sujeto en ese contexto favorable agota el universo mismo del discurso -omnipersonalidado queda indeterminada".

Como es de sobra conocido, el español posee distintos recursos para expresar impersonalidad $^{4}, \mathrm{y}$, entre ellos, el pronombre indefinido $u n o^{5}$ ha sido tema de interés de muchos investigadores (Morales de Walters 1992, 1995; Fernández 2008; Flores-Ferán 2009, entre otros). No obstante, los resultados de algunos estudios sobre ese mecanismo de impersonalización en distintas variedades del español se muestran contradictorios. Por un lado, Lorenzo (1984) y Morales de Walters (1995) advierten de un desplazamiento de las formas uno junto con el se por el uso de tú en el habla de España y Puerto Rico. En la misma línea, coincide Posio (2017), quien se centra en las diferencias de uso de uno y tú en español y portugués. Para el español, este autor (2017: 218) afirma que el empleo de uno "es cada vez menos frecuente en los registros coloquiales del español

4. Se trata de mecanismos como el tú y el se impersonal, el usted o el infinitivo (León-Castro 2012, 2015). Para más detalles, véase bibliografía.

5. Al pronombre uno como mecanismo de impersonalización, le corresponden en inglés one, en francés on o en alemán la palabra man. Para el inglés, Jespersen (1975: 257) justifica esta expresión señalando que el hablante (YO) en ocasiones prefiere dejar su persona, "en el fondo a pesar de que lo que se expresa es la primera persona más que otra cosa". Sobre el pronombre on en francés, Riegel, Pellat y Rioul (1994: 197) afirman que:

"Sa valeur de base est, en effet, celle d'un pronom indéfini renvoyant à une personne ou à un ensemble de personnes d'extension variable, que le locuteur ne peut ou ne veut pas identifier de façon plus précise [...] Cette indétermination le rend apte à fonctionner comme substitut de tous les autres pronoms personnels en rejetant leur référent dans l'anonymat". 
peninsular donde se prefiere el tú impersonal" " 6 . Por otro lado, otros estudios han evidenciado un predominio del indefinido uno en el español de los venezolanos de Caracas (Guirado 2011), en el habla de los colombianos de Miami y Bogotá (Hurtado 2012) o en la de Barranquilla (Hurtado y Gutiérrez-Rivas 2016).

\section{Metodología y corpus analizado}

\subsection{Corpus y selección de casos}

El objetivo de este trabajo consiste en estudiar la forma pronominal uno como estrategia de impersonalización en la comunidad urbana de Sevilla, dado que creemos que se trata de un mecanismo bastante recurrente. Para llevar a cabo este análisis, utilizamos 72 entrevistas semidirigidas, recogidas entre 2009 y 2018 y que forman parte del Corpus oral PRESEEA-Sevilla. Cada una de las grabaciones tiene una duración de aproximadamente 45 minutos. Las tres variables sociales que utilizamos en este análisis son: sexo, edad y nivel de instrucción. La distribución por cuota de hablantes en la muestra analizada se refleja en la Tabla 1:

Tabla 1. Distribución de los informantes en el corpus PRESEEA-SE

\begin{tabular}{|l|c|c|c|c|c|c|}
\hline 72 hablantes & \multicolumn{2}{|c|}{ Sociolecto alto } & \multicolumn{2}{c|}{ Sociolecto medio } & \multicolumn{2}{c|}{ Sociolecto bajo } \\
\hline Edad & Hombre & Mujer & Hombre & Mujer & Hombre & Mujer \\
\hline 20 - 34 años & 4 & 4 & 4 & 4 & 4 & 4 \\
\hline $35-54$ años & 4 & 4 & 4 & 4 & 4 & 4 \\
\hline$>$ 55 años & 4 & 4 & 4 & 4 & 4 & 4 \\
\hline
\end{tabular}

Según las pautas metodológicas de PRESEEA, pertenecen al sociolecto bajo los hablantes, sin estudios, con estudios primarios o con graduado escolar. El sociolecto medio se atribuye al conjunto de personas que tienen bachillerato o formación profesional. Asimismo, se ha incluido a los que tienen un mínimo

6. Posio (2017) se centra en el Corpus de habla culta de Salamanca (Fernández 2005) basado en entrevistas sociolingüísticas: los informantes tienen entre 30 y 72 años y un nivel de instrucción alto. La frecuencia de las dos construcciones muestra el predominio del tú impersonal en detrimento de la forma uno: se documentaron, respectivamente, 660 y 12 veces en el corpus. La mitad de las 12 ocurrencias de uno proceden del mismo informante (un varón de 72 años). 
inicio de estudios superiores (licenciatura o grado). Por último, el sociolecto alto corresponde a los informantes con estudios universitarios finalizados, máster y/o doctorado ${ }^{7}$.

Una vez seleccionados los ejemplos, se han eliminado los casos cuando:

a) el pronombre remite a una persona determinada;

b) el informante retoma para contestar las palabras del entrevistador en las que aparece el indefinido uno, ya que no se sabe con exactitud si su intención era utilizar esta forma;

c) el hablante vacila en su discurso y deja la secuencia incompleta;

d) se trata de una repetición del mismo fenómeno. En este caso, se ha computado el mecanismo una sola vez.

Se han descartado también los casos donde no queda claro cómo analizar el pronombre uno. La presencia de la forma que en el ejemplo /1/ podría indicar algún tipo de modificación oracional:

(1) entonces / fíjate para venir del < vacilación/> Prado de San Sebastián a donde está eso hasta < vacilación/> hasta la Plaza del Duque no va a tener uno que <ininteligible/> (SEVI_H31_012).

Por tanto, en las 72 entrevistas manejadas en este estudio, se han localizado 192 ejemplos de uno y cada uno que analizaremos a lo largo de este trabajo.

\subsection{Criterios de análisis y procesamiento}

Para ver qué factores favorecen las distintas lecturas del indefinido uno tanto en su vertiente generalizadora como en aquella que reduce el papel del hablante en su discurso, hemos considerado los siguientes criterios?:

1. Sintácticos. Nos hemos centrado en la categoría semántica del verbo, ya que muestra, entre otros, si el uso de uno impersonal "se relaciona con un

7. Véase también http://preseea.linguas.net/Portals/0/Metodologia/METODOLOG\%C3\%8DA\%20 PRESEEA.pdf.

8. Se ha considerado cada uno variante de uno, solo en los casos en que cada actúa como un indefinido distributivo (Martínez Ripoll 1999: 502). Según Hernández (1998: 51), el empleo de cada con valor distributivo "es un uso poco claro que se mezcla, a menudo, con el valor de generalización" [apud Sinner 2013: 242].

9. Véase también León-Castro y Repede (2018). 
posicionamiento particular del hablante: con sus actitudes, sentimientos, estados, creencias y valoraciones" (Hurtado y Gutiérrez-Rivas 2016: 43). No obstante, por la escasez de representación en el corpus nos vimos obligados a no incluir en el análisis estos cinco condicionantes:

a) función del pronombre uno, mayoritariamente como sujeto;

b) uso mayoritario del pronombre con formas no perifrásticas;

c) predominio de la forma indefinida en oraciones subordinadas.

2. Pragmáticos. Hemos tomado en consideración los siguientes criterios: el tipo de secuencia discursiva y la temática de la conversación. La primera nos permite observar si el indefinido uno se emplea para ocultar la identidad del yo en los temas más subjetivos (narraciones personales) y para generalizar en los discursos argumentativos (temas generales). Basándonos en León-Castro y Repede (2018), hemos delimitado tres circunstancias:

a) el hablante relata sucesos o hechos anclados en un espacio y un tiempo distintos a los de él, donde predominan las acciones y la función representativa (Adam 1992):

(2) por ejemplo / eh $<$ alargamiento/ $>$ yo recuerdo que en otro tiempo / uno / podía hacer una $<$ alargamiento/ $>$ / no sé / un<alargamiento/> grupo de personas / una familia / un grupo de amigos / podía hacer una barbacoa en cualquier sitio y en cualquier época del año (SEVI_H33_060).

b) el informante presenta o desarrolla un razonamiento particular, cuyo propósito consiste "en influir de alguna forma en las ideas de los oyentes, modificar su conocimiento del mundo y convencerlos” (Gallucci y Vargas 2015: 80).

(3) y es < vacilación/> el truco está en no consumir las patatas alioli rápidamente / sino esperar al menos seis o siete horas para que / eh se / compasen todos los ingre<palabra cortada/> para que se unan todos los ingredientes / como digo yo / a nivel molecular $<$ risas = "E" / $>$ / para que / pueda tener sabor que uno va buscando / es decir / uno exquisito / $\mathrm{y}<$ alargamiento/ $>\mathrm{y}$ ese es el / truco / para mí ¿eh? / eh de <vacilación/> de hacer las papas $<$ vacilación/> las patatas alioli (SEVI_H23_056).

c) el sujeto expresa opiniones, creencias o pensamientos. Se trata de los casos en que uno forma parte de una secuencia narrativa y muestra una opinión o un pensamiento: 
(4) entonces $<$ alargamiento/ $>$ eso de que<alargamiento/> / uno sí se puede sentir más seguro / no sé yo $<$ alargamiento $>$ dónde me sentiría más seguro en $<$ alargamiento $>/<$ ruido $=$ "chasquido_ boca"/> ¿en Turquía o en Marruecos o<alargamiento/> o en Nueva York? (SEVI_H33_058).

En cuanto a la temática de la conversación, se han clasificado los ejemplos según aparezcan en un contexto donde se aborden temas generales (el tiempo, la ciudad, la Semana Santa, etc.):

(5) E: ¿tú crees que hay más delincuencia ahora que antes?

I: pues $<$ alargamiento/ $>$ mmm no / yo no lo he notad $<$ palabra_cortada/ $>$ yo no he notado $<$ alargamiento $>>$ que haya un cambio $<$ alargamiento $>$ grande ¿no? los años en los que yo / vivo ¿no? pero<alargamiento/> quizás $<$ alargamiento/ $>$ antiguamente pues la gente no $<$ alargamiento/ $>$ se metía tanto $<$ alargamiento/ $>$ en robar ¿no? / cada uno era lo suyo / ahora pues bueno $/$ no sé será la crisis $/$ que también $<$ alargamiento $/><$ risas $=$ "I"/> le hace falta dinero a la gente (SEVI_M12_037).

O se traten temas que pertenecen a la esfera íntima del hablante (su trabajo, su familia, su casa, etc.):

(6) E: uhum ¿conservas tus amigos desde pequeña?

I: sí / sí / eh<alargamiento/ $>$ del colegio / pocas / menos de los que tenía antes / porque $<$ alargamiento $/>$ claro / cada uno va $<$ alargamiento/ $>$ haciendo su vida y es difícil ¿no? pero sí que conservo < ruido = "tos"/> (SEVI_M12_037).

3. Sociales. Como ya se ha mencionado previamente, se han considerado tres parámetros: edad, sexo y nivel de instrucción.

4. Estilísticos. Nos hemos centrado en el condicionante tenor, esto es, participantes conocidos o desconocidos en la interacción.

Asimismo, para ver qué relación existe entre los criterios anteriores y su aplicación a la finalidad del hablante con respecto al pronombre uno realizamos una tabulación cruzada. Aplicamos también la prueba de $\mathrm{x}^{2}$ de Pearson que nos permite determinar si las frecuencias observadas en la tabla cruzada presentan significación estadística o no. En este caso, los resultados de los criterios no deben superar el límite de $0,05^{10}$.

10. Para los casos con menos de cinco ejemplos, hemos aplicado también la prueba exacta de Fisher. 


\section{El impersonalizador uno: interpretación semántica}

El empleo de la forma pronominal uno, según la intención con la que se utilice, implica "un desplazamiento de su referencia habitual o bien el enunciado en el que se inserta cobra un valor de verdad, en principio, universal" (León-Castro 2012: 25). En este caso, el indefinido adquiere distintos valores semánticos, de modo que se presentan diferentes niveles de impersonalización.

\subsection{Encubrimiento pragmático}

Una de estas interpretaciones posibles aparece cuando el hablante se refiere a sí mismo (el yo incluido) ${ }^{11}$, pero oculta su identidad detrás de sus palabras con fines diferentes. Así, el sujeto busca acuerdo o aceptación lingüística y social por parte del interlocutor, como en el ejemplo /7/:

(7) no creo que sean buenos los < vacilación/> las prisas / las < vacilación/> los agobios / los < vacilación/ $>$ los // y ahora que está uno jubilado y no es obligatorio lo que estás haciendo / pues tampoco me gusta $<$ alargamiento/ $>$ ahí<alargamiento/ $>$ meterle E: $<$ tiempo $=$ "31:14"/> claro

I: el látigo ¿no? < simultáneo $>$ a las $<$ vacilación $/><$ risas $=$ "I" $/></$ simultáneo $>$ (SEVI H33_059).

Sirve para proteger o defender la imagen del hablante de posibles críticas. El informante observa que su imagen se ve atacada o desfavorecida por lo dicho previamente e intenta salvaguardarla, como en $/ 8 /$, donde el hablante trata de justificar su actitud para evitar ser considerado una persona conflictiva:

(8) E: uhum ¿alguna vez te has visto dentro de un atraco / alguna pelea o algo así?

I: sí

E: ¿y qué pasó?

I: en unas varias pero vamos nunca por mí / siempre por defender amigos eso / ya de juventud y nada en una en me ha < vacilación $>$ una me han currado y en otras hemos y en otra hemos currado

$\mathrm{E}:<$ risas $=$ "E" $>>$ ¿y cómo es eso?

I: nada pues pelea en la discoteca defendiendo a uno / no sabe uno ni <vacilación/>

11. Puede identificarse con un tipo de atenuación que Briz Gómez (1998: 154-156) 1lama, como se ha visto, impersonalización del yo. 
ni por qué se está por qué se está peleando ya uno / ya <vacilación/> y nada salí escalabrado y me llevé punto en la cabeza (SEVI_H21_005).

Asimismo, hemos documentado ejemplos en los que el informante establece una cierta crítica, pero al mismo tiempo quiere reducir su compromiso sobre lo dicho o atenuar su propia opinión para evitar posibles consecuencias:

(9) es verdad que la construcción / pues es un poco singular / quizá / $\mathrm{mmm} \mathrm{/} \mathrm{demasiado}$ moderna para un sitio tan tradicional como es aquel / eh / está<alargamiento/> al lado de la iglesia de la Anunciación / al lado de / la antigua casa de los jesuitas hoy / eh / eh / mmm / Universidad de Be<palabra_cortada/ $>$ de Bellas Artes / eh / quizá desentona un poco / en medio de <vacilación/ $>$ de aquella zona arquitectónica / pero la verdad es que cada vez que va pasando el tiempo / pues uno se va acostumbrando y va encajando mejor ¿no? / y < vacilación/> y tiene su sitio (SEVI_H32_035).

Así, con el empleo del indefinido uno en /9/ se suaviza una crítica con respecto a la construcción de Las Setas en el centro de Sevilla.

\subsection{Generalización}

A menudo el hablante utiliza este mecanismo impersonalizador para expresar generalizaciones que pueden ser de dos tipos según se incluya o no a sí mismo en el grupo al que se refiere.

\subsubsection{Generalización inclusiva}

Las generalizaciones inclusivas muestran afirmaciones con las que el propio emisor se identifica. Su pertenencia al grupo se percibe más claramente cuando el mecanismo impersonalizador se combina en el discurso con marcas de primera persona del plural; incluso puede aparecer como sujeto de una forma verbal con estas marcas:

(10) cada uno somos de nuestro padre y nuestra madre / pero bueno / siempre que tú te pegas a un grupo de personas o a una persona / siempre vas buscando una afinidad con ella/ si no tienes afinidad con esa persona / bueno sí / para tomarte una cerveza te la tomas con cualquiera / pero hasta ahí y punto (SEVI_H12_026). 
La implicación del hablante también se evidencia cuando vincula sus propias vivencias con la generalización emitida. Sea en los casos en que utiliza su propia experiencia para ejemplificar y apoyar la generalización:

(11) I: en general<alargamiento $/>$ y digan lo que digan $/$ eh $<$ ruido $=$ "especie de golpe" $/>$ se ve como una fiesta popular / toda la gente lo toma como una fiesta popular / no lo toman como $<$ alargamiento/ $>$ una fiesta religiosa // después que sea religiosa o no sea religiosa / pues no lo sé E: uhum

I: eso según cada uno para adentro pensará y según como lo sienta // para mí es una fiesta popular no $<$ alargamiento/ $>$ / no lo noto como $<$ alargamiento/ $>$ religiosa $(\mathrm{SEVI}$ H12_025).

Sea a la inversa, esto es, ejemplos en los que la generalización sirve para reforzar su opinión o experiencia sobre un tema determinado:

(12) I: la Navidad me gusta la segunda parte la $<$ alargamiento $>$ tema la fiesta de los reyes la $<$ alargamiento $>$ primera parte $<$ alargamiento $>$ también no es que no me guste la navidad me gusta el ambiente me gusta pasear por el centro

E: uhum

I: me gusta $<$ alargamiento $>$ me gusta la navidad en sí / lo que no me gusta son las fiestas de la navidad<silencio/> pienso que como cada vez uno va creciendo y va perdiendo familiares (SEVI_H21_007).

Asimismo, el hablante generaliza con mucha frecuencia para emitir una crítica, como en el ejemplo /13/:

(13)I: el problema es que no nos adaptamos a lo que tenemos / que es una enfermedad muy grande

E: uhum

I: eso es una enfermedad muy grande no adaptar lo que tiene uno quiere más / pero tú tendrás que adaptarte a tus posibilidades y es que están viviendo por encima de sus posibilidades o estamos viviendo / por encima de nuestras posibilidades y ahí viene el problema (SEVI_H31_009).

en el que se trata el tema de la crisis y, según el informante, "lo que pasa es que nos hemos ido<alargamiento/> volviendo locos” (SEVI_H31_009). 


\subsubsection{Generalización exclusiva}

A veces el hablante se refiere a un grupo al que no pertenece y en esos casos, la aparición de la tercera persona en el contexto contribuye a interpretar el valor generalizador exclusivo de uno:

(14) I: ahora / toca $<$ alargamiento/ $>$ ya se sabe que $<$ alargamiento/ $>$ eso es así<alargamiento/> / que hay que jugar mucho para que le toque a uno / o sea que $<$ alargamiento/ $>$ / o sea que / el que juega y se < vacilación/> ahí<alargamiento/> cree que<alargamiento/> va a sacarle rentabilidad es que está<alargamiento/> // es por si le toca vamos / y también $\mathrm{u}<$ palabra_cortada/ $>$ / una pequeña $<$ alargamiento/ $>$ distracción por / mirar los números y eso (SEVI_H22_033).

Una finalidad habitual cuando se expresan generalizaciones de este tipo es transmitir una crítica; esto es, valorar unos hechos con los que no se identifica:

(15) I: yo no suelo ir mucho por allí // pero / de oídas / $\mathrm{mmm} /$ hay algunas calles que allí hay muchos / bares / muchas salas de / baile / eh <alargamiento/> / muchas discotecas / que los chavales se llevan hasta las tantas y / luego pierden un poco el control / allí se reúnen / de muchas < vacilación/> / sitios / cada uno tiene sus / ideas / y / después se descontrolan un poco (SEVI_M31_021).

Todas las funciones descritas anteriormente quedan reflejas en el Gráfico 1:

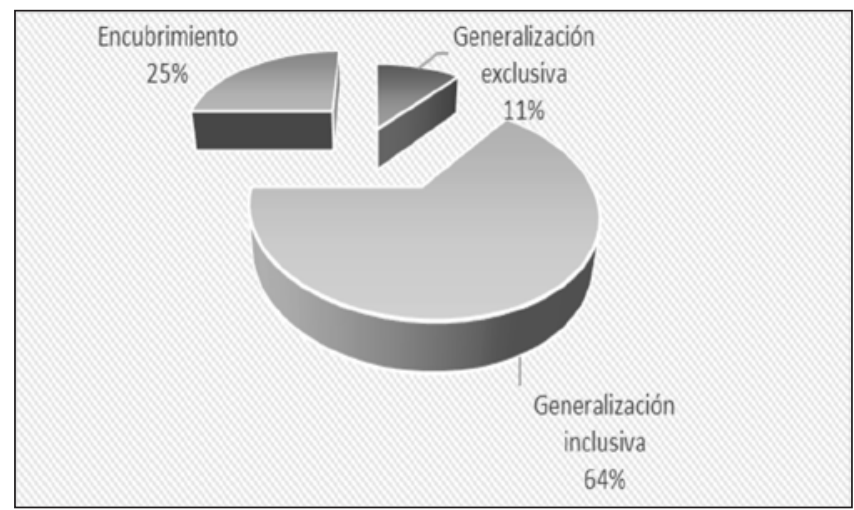

Gráfico 1. Interpretación semántica de uno en el corpus oral PRESEEA-SE. 
Así, en las 72 encuestas manejadas para este estudio y que forman parte del corpus PRESEEA en la ciudad, el pronombre uno aparece relacionado en menor medida con la generalización exclusiva, esto es, se han localizado 21 ocurrencias. Para el encubrimiento pragmático, se han documentado 48 casos, y 123 ejemplos de generalización inclusiva.

\section{Análisis del impersonalizador uno en el corpus PRESEEA-SE}

\subsection{Criterios sintácticos}

Con respecto a los parámetros sintácticos, como ya se ha mencionado anteriormente, hemos considerado la clasificación semántica de los verbos. Hemos partido de la frecuencia de uso de estos verbos en el corpus manejado para después clasificarlos en verbos de entendimiento, estado, afección psíquica, actividad y movimiento ${ }^{12}$. Por tanto, del total de verbos documentados en las secuencias con el pronombre uno, 43 son verbos de estado (ser o estar), 44 son de afección psíquica (sentir, preocuparse), 57 indican actividad, sobre todo hacer, 25 son de movimiento (desplazarse, ir, llegar, venir) y 23 de entendimiento que incluye a los de opinión y creencias o los procesos mentales (aprender, conocer, pensar, saber, etc. $)^{13}$.

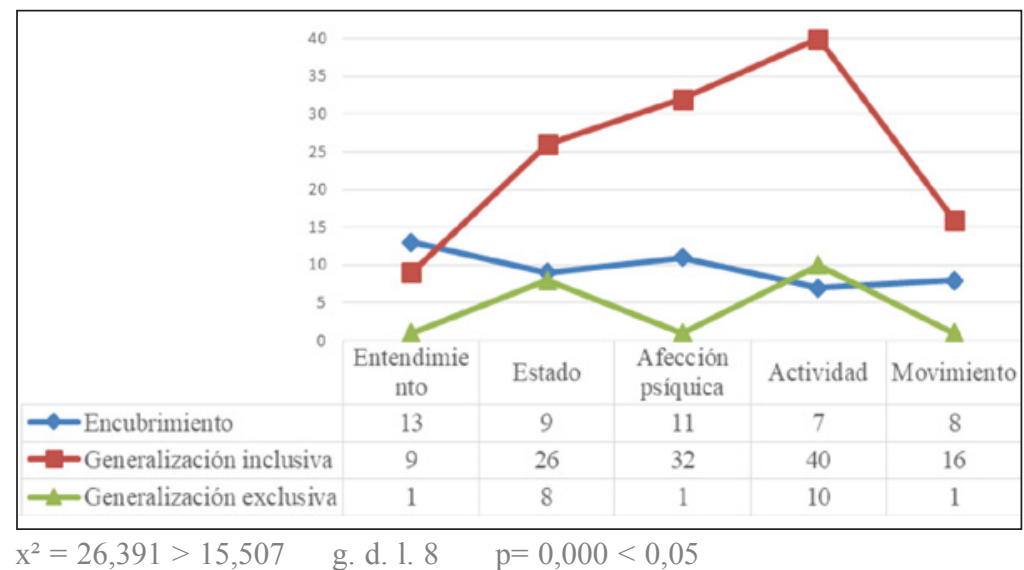

Gráfico 2. Relación entre las lecturas de uno y la clase semántica del verbo

12. Para más detalles, véase León-Castro y Repede (2018).

13. Dada la poca representación de los verbos modales en los materiales utilizados, no se ha considerado como una clase semántica distinta, sino que, para clasificarlos, nos hemos basado en la semántica del verbo auxiliado. 
Al emplear la forma indefinida uno para manifestar sus experiencias, creencias, emociones y/actitudes, el hablante "se mueve entre un contenido subjetivo (ocultamiento de identidad del yo) hasta objetivo (generalización exclusiva)" (León-Castro y Repede 2018: 77). Así, para el valor de encubrimiento, del total de casos $(\mathrm{N}=48)$, la forma pronominal aparece más con verbos de entendimiento $(27,08 \%)$ y afectivos $(22,95)$.

\footnotetext{
El contenido léxico de estos verbos indica conocimiento, evaluación y sentimientos personales y están intrínsecamente relacionados con las experiencias y vivencias del hablante, de modo que la persona responsable de lo dicho prefiere esconder su identidad detrás de sus palabras como mecanismo de autoprotección o en busca de acuerdo o aceptación social (ibídem).
}

Los verbos de actividad y de movimiento aparecen menos relacionados con esta función semántica de uno, pues se trata de verbos que favorecen una lectura más genérica: esto es, $14,58 \%$ y $16,67 \%$, respectivamente.

Si nos fijamos en la interpretación generalización inclusiva, los informantes prefieren utilizar esta forma pronominal con verbos dinámicos (32,52\%). En este caso, podríamos afirmar que "se trata de acciones que realiza el común denominador de las personas y de las que el sujeto forma parte" (ibídem). También observamos, según el Gráfico 2, el empleo de verbos afectivos $(20,02 \%)$ y de estado $(21,14 \%)$ que parece relacionarse "con el nivel de implicación del individuo dentro de la sociedad y su identificación con un grupo de personas que comparten una serie de características o circunstancias comunes" (ibídem). Menor efecto tienen los verbos de movimiento $(13 \%)$ y los de entendimiento $(7,31 \%)$.

Para la última lectura -generalización exclusiva-, el uso mayor del impersonalizador uno con verbos de estado $(38,1 \%)$ o actividad $(47,62 \%)$ remite "a una situación general que contrasta con una realidad personal o individual del hablante" (ibídem).

\subsection{Criterios pragmáticos}

Los dos criterios pragmáticos que se han tenido en cuenta para el análisis de nuestro corpus han sido el tipo de secuencia discursiva en que aparece el mecanismo uno y la temática que aborda el hablante cuando lo emplea. Con respecto al primero, según el Gráfico 3, se observa que el impersonalizador 
uno se utiliza un $35,94 \%$ en secuencias narrativas, un 38,02\% en secuencias argumentativas y un $25,52 \%$ cuando se expresan opiniones.

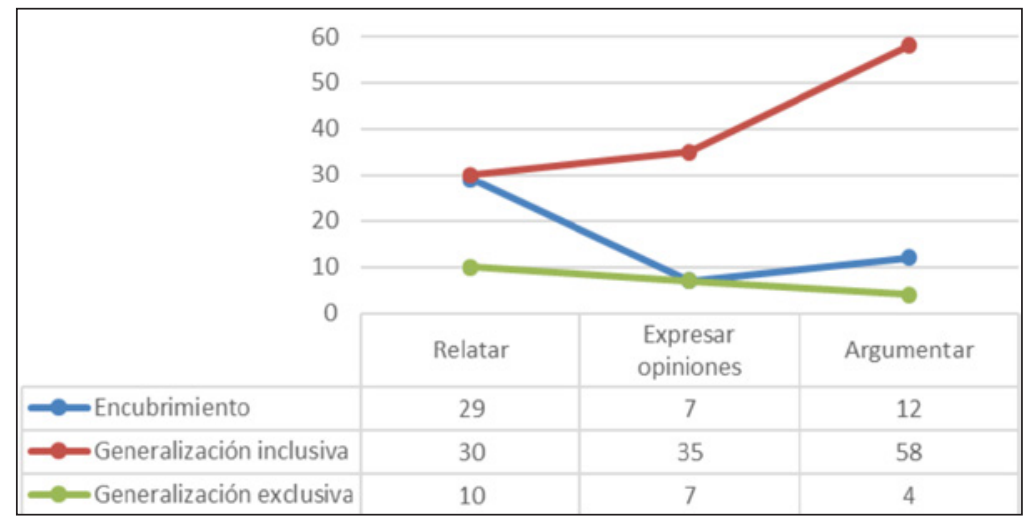

$x^{2}=23,074>9,877 \quad$ g. d. $1.4 \quad p=0,000<0,05$

Gráfico 3. Valores de uno y secuencia discursiva.

Si nos centramos en la lectura ocultamiento de la identidad del hablante, se manifiesta un uso mayor del pronombre uno cuando el informante narra hechos relacionados con sus experiencias o vivencias, esto es, el 60,42\% de los casos $(\mathrm{N}=48)$. Así, el empleo de la forma indefinida se relaciona no solo "con un valor afectivo alto, ya que al tratarse de información personal existe un nivel mayor de implicación del hablante en sus narraciones, sino también con una mayor activación del escudo autoprotector: recurre a este mecanismo para defender o salvaguardar su imagen de posibles críticas" (León-Castro y Repede 2018: 81). No obstante, encontramos porcentajes menores para los casos en que el hablante argumenta $(25 \%)$ o expresa pensamientos $(14,58 \%)$.

Con respecto a la referencia-generalización inclusiva- $(\mathrm{N}=123)$, el porcentaje disminuye en las narraciones $(24,39 \%)$, pero crece progresivamente cuando expresa opiniones o creencias $(28,46 \%) \mathrm{y}$, especialmente, cuando argumenta $(47,15 \%)$. En cambio, para la generalización exclusiva $(\mathrm{N}=21)$, se percibe una tendencia contraria: encontramos un 47,62\% cuando el hablante relata hechos o sucesos, un 33,33\% cuando expresa sus opiniones y 19,05\% para la función de argumentar.

En cuanto al segundo criterio, ha de tenerse en consideración que, por el tipo de entrevista semidirigida que se ha llevado a cabo en las grabaciones, se tratan siempre unos mismos temas, algunos de ámbito público y otros que 
pertenecen a la esfera privada del informante. A priori podríamos pensar que esta característica condiciona el valor de uno en el discurso, de manera que se emplearía como encubridor pragmático cuando el informante habla de su vida y lo utilizaría como generalizador en temas que trascienden su intimidad.

En primer lugar, se percibe una aparición del fenómeno muy desigual según la temática abordada. Así pues, el 69,2\% de los ejemplos analizados $(\mathrm{N}=192)$ se emplea en situaciones comunicativas que sobrepasan el ámbito privado del hablante y tan solo el $30,8 \%$ se refieren a temas relativos a su intimidad.

En segundo lugar, de los ejemplos clasificados en una temática pública $(\mathrm{N}=133)$, una amplia mayoría se utilizan con un valor generalizador inclusivo $(71,4 \%)$ y el resto de los casos se reparten por igual entre las otras dos interpretaciones posibles $(14,3 \%$ para el encubrimiento y $14,3 \%$ para la generalización exclusiva). Sin embargo, en los ejemplos pertenecientes al ámbito privado $(\mathrm{N}=59)$, el mecanismo se emplea casi por igual tanto para generalizar (el propio hablante se incluye en el grupo) como para ocultarse en el discurso; esto es, $47,4 \%$ con una intención generalizadora inclusiva y $49,1 \%$ con una intención encubridora. Tan solo el 3,5\% de los casos expresan una generalización exclusiva (es lógico si tenemos en cuenta que se están tratando temas cotidianos con los que el hablante suele identificarse). En el Gráfico 4 ofrecemos los resultados que hemos obtenido a partir de la distinción entre ámbito público y ámbito privado:

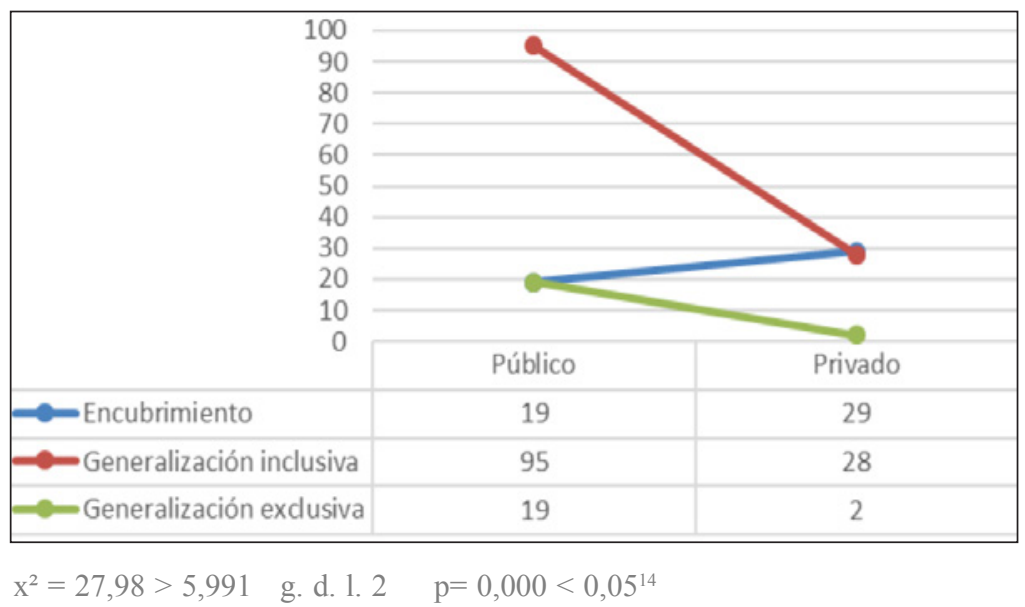

Gráfico 4. Valores de uno y temática de la conversación.

14. El valor de $p$ es también 0,000 , según la prueba exacta de Fisher. 
A la luz de estos resultados, y como ya se indicó en León-Castro y Repede (2018), creemos que existen dos factores que influyen en el empleo y el valor que adquiere uno en el contexto:

1. La formulación de la pregunta. Algunos entrevistadores abordan los bloques temáticos de manera general:

(16) E: ¿son iguales los amigos que se tienen de pequeño que los que se tienen de mayor? I: < silencio/> / creo que no / de pequeño / eh / uno tiene una $<$ vacilación/ $>$ un concepto de la vida / y de mayor tiene otro (SEVI_H32_035).

Y otros buscan un mayor compromiso por parte del informante:

(17) E: uhum ¿tú crees que las amistades que tienes de pequeña son las mismas de cuando te vas haciendo mayor?

I: $m m m$ no<alargamiento/> y sí / a ver yo tengo amigas de cuando<alargamiento/> pequeña que siguen siendo ahora igual de amigas ¿no? pero también es verdad que $<$ alargamiento/ $>$ la gente cambia / y que cada uno tira por un camino / y que a lo mejor a ti no te interesa (SEVI_M12_037).

2. El grado de implicación del entrevistado. El hablante puede tratar un tema cualquiera, pertenezca o no a su esfera íntima, desde su propia experiencia o perspectiva, lo que tiene consecuencias en las posibles selecciones que lleve a cabo de mecanismos de indefinición referencial, como uno:

(18) I: lo que hay hoy en el Hospital de los Venerables / vienen cuadros prácticamente de todo $<$ alargamiento/ $>$ de todas las pinacotecas más importantes que hay en $<$ vacilación/ $>$ en Europa // y<alargamiento/> y hombre / por un lado / tiene uno la sensación agridulce de pensar que $<$ ruido $=$ "chasquido_boca" $>>$ viendo cómo se trata el patrimonio aquí en Sevilla / pues a lo mejor sabe Dios cómo estarían hoy esas obras de arte y sin embargo / hoy están en perfecto estado de < vacilación/> de conservación en otros museos europeos que < vacilación/> que sí han sabido valorar (SEVI_H23_053).

En el ejemplo $/ 18 /$, el informante habla sobre el patrimonio cultural de Sevilla y da su opinión al respecto. Sabedor de que es muy posible que quienes lo escuchen no estén de acuerdo y puedan atacarlo, trata de suavizar su crítica, por lo que emplea uno para ocultar su presencia en el discurso. 
Asimismo, nos ha parecido interesante realizar un cruce de variables entre el tipo de secuencia discursiva y la temática conversacional. Los resultados se muestran en el Gráfico 5:

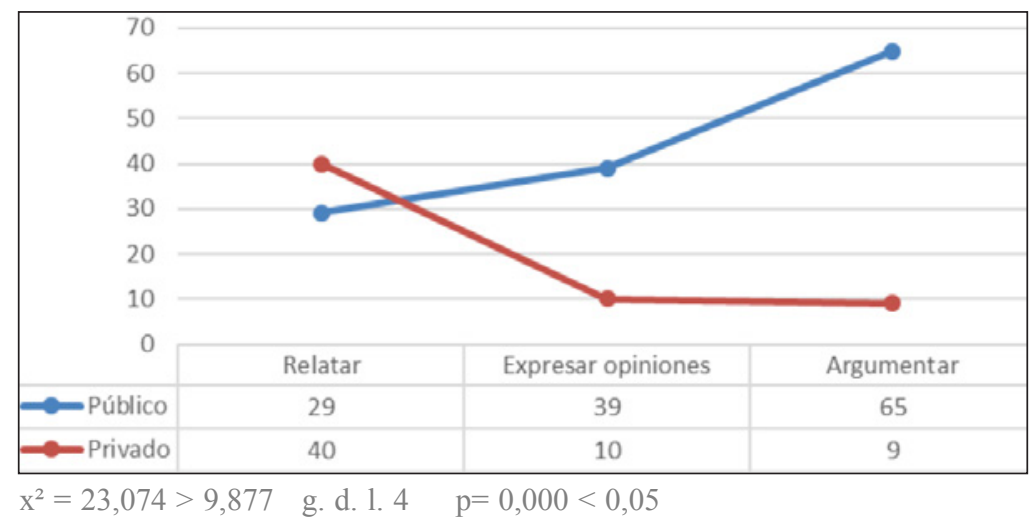

Gráfico 5. Temática de la conversación y secuencia discursiva.

Así, podemos observar que los informantes encuestados utilizan menos la forma indefinida cuando narran hechos relacionados con el ámbito público $(21,80 \%)$. En cambio, encontramos porcentajes mayores cuando se exponen creencias $(29,32 \%)$ o se presentan argumentos $(48,87 \%)$. No obstante, parece manifestarse la tendencia contraria con respecto al ámbito privado. Así, del total de ocurrencias $(\mathrm{N}=59)$, el $67,8 \%$ corresponde a la secuencia narrativa. A esta última le siguen en orden decreciente, pero por debajo, los casos de expresar opiniones $(16,95 \%)$ y argumentar $(15,25 \%)$.

\subsection{Criterios sociales}

Con relación al criterio sociolingüístico, hemos tenido en cuenta tres factores: edad, sexo y nivel de instrucción. Solo el análisis de este último ha resultado significativo con relación a la función semántica del mecanismo uno. No obstante, hemos considerado pertinente incluir algunas cuestiones interesantes en el estudio de cado uno de estos parámetros.

Para el factor edad, se ha observado un predominio del mecanismo en el tercer grupo etario $(44,8 \%)$, tanto en los hombres como en las mujeres, y su empleo va descendiendo cuando la edad del informante también es menor: $34,4 \%$ de los ejemplos analizados en el segundo grupo y 20,8 en el primero. Según los datos que se muestran en el Gráfico 6: 


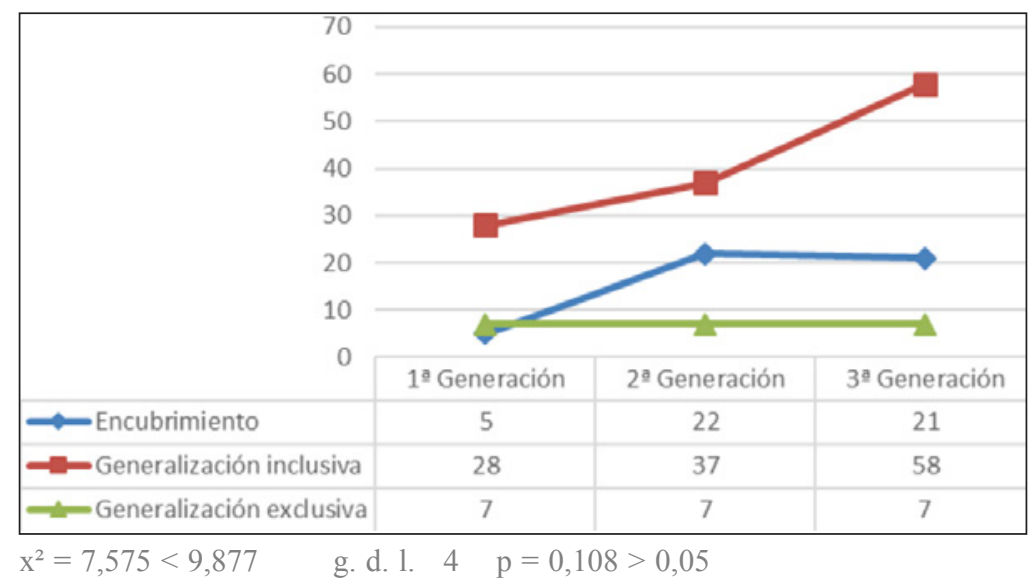

Gráfico 6. Valores de uno y grupo generacional.

los informantes de todas las edades prefieren el empleo de uno para la generalización inclusiva; para la segunda y tercera generación, va seguida del encubrimiento pragmático, y son minoritarios los casos en que se utiliza para una generalización exclusiva. En cambio, observamos un comportamiento diferente entre los hablantes de la primera generación: mantienen en primer lugar la interpretación generalizadora inclusiva en el $70 \%$ de los casos analizados $(\mathrm{N}=40)$ y, además, y las otras dos aparecen escasamente con una mínima diferencia entre ellas (17,5\% para la generalización exclusiva y $12,5 \%$ para el encubrimiento).

Para el sexo, es un recurso más empleado por hombres $(64,5 \%)$ que por mujeres $(35,5 \%)$. Si nos fijamos en el Gráfico 7:

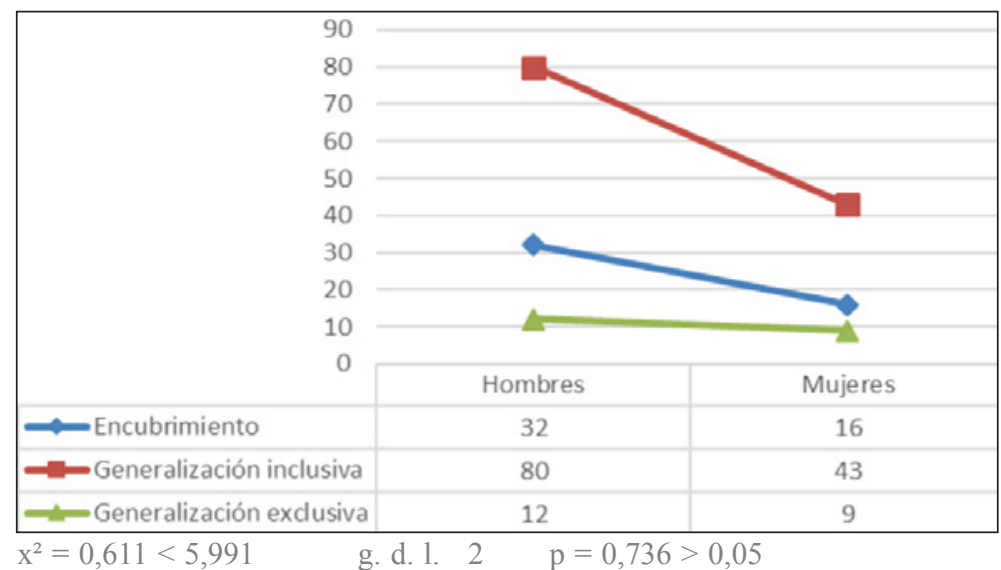

Gráfico 7. Funciones de uno y sexo. 
para las generalizaciones inclusivas $(\mathrm{N}=123)$, se percibe un empleo mayoritario por parte de los hombres (65\%) que de las mujeres (35\%). Los resultados son semejantes para las otras dos interpretaciones. En cuanto al encubrimiento pragmático $(\mathrm{N}=48)$, el $66,6 \%$ de los ejemplos corresponden a hombres y solo el 33,4\% a mujeres, y para la generalización exclusiva $(\mathrm{N}=21)$, siguen siendo los hombres quienes hacen un mayor uso del mecanismo $(57,1 \%$ vs. $42,8 \%$ de las mujeres).

Si nos centramos en las mujeres $(\mathrm{N}=68)$, prefieren el empleo del mecanismo impersonalizador en masculino (como género no marcado) en la mayoría de casos $(78 \%)^{15}$. Tan solo se han registrado 15 ejemplos $(22 \%)$ de la variante una entre las informantes de los tres sociolectos, de los cuales 10 se han analizado con una interpretación encubridora y 5 como generalizadores inclusivos. Para ambos valores se han encontrado ejemplos pertenecientes a temáticas públicas y privadas:

(19) I: hombre de la primavera me gusta por supuesto que empieza el buen tiempo y empiezan a alargarse los días// la primavera en Sevilla es muy bonita/ se vive muy bien porque empieza/ hombre/ a florecer todo ¿no? Parece que una tiene ganas ya de soltar los abrigos y de ponerse al descubierto y que venga el solito y < vacilación $>$ y la semana santa/ la feria/ hombre de primavera me gustan bastantes cosas (SEVI_M21_020).

(20) I: vamos / de hecho hasta Humahuaca me lo llevé / el burro llevaba mi cepillo / llevaba mi cepillo eléctrico

E: ¡qué barbaridad!

I: con pilas / pero yo me lavaba mis dientes $<$ alargamiento/ $><$ risas $=$ "I" $>>$ con mi cepillo eléctrico / cada una hace su<alargamiento/> escala de prioridades y la mía es mi cepillo eléctrico (SEVI_M13_062).

En el ejemplo /19/, se está hablando del tiempo y se emplea el mecanismo con un valor encubridor y en $/ 20 /$, la informante relata su voluntariado en Humahuaca y lo utiliza con una interpretación generalizadora.

Asimismo, del total de ocurrencias con la forma una $(\mathrm{N}=15), 11$ casos aparecen en secuencias narrativas y los 4 restantes en secuencias en las que la hablante expresa sus opiniones o pensamientos. No se ha localizado ningún ejemplo para la función argumentativa.

15. El empleo más frecuente de uno no impide que aparezcan marcas femeninas que remiten directamente a la emisora y reflejan su presencia en el discurso. Véase León-Castro y Repede (2018). 
En el Gráfico 8 se muestran los datos obtenidos para el nivel educacional. Se observa, así, que el sociolecto alto utiliza esta forma un $34,89 \%$, el medio un $32,29 \%$ y el bajo un $32,81 \%$.

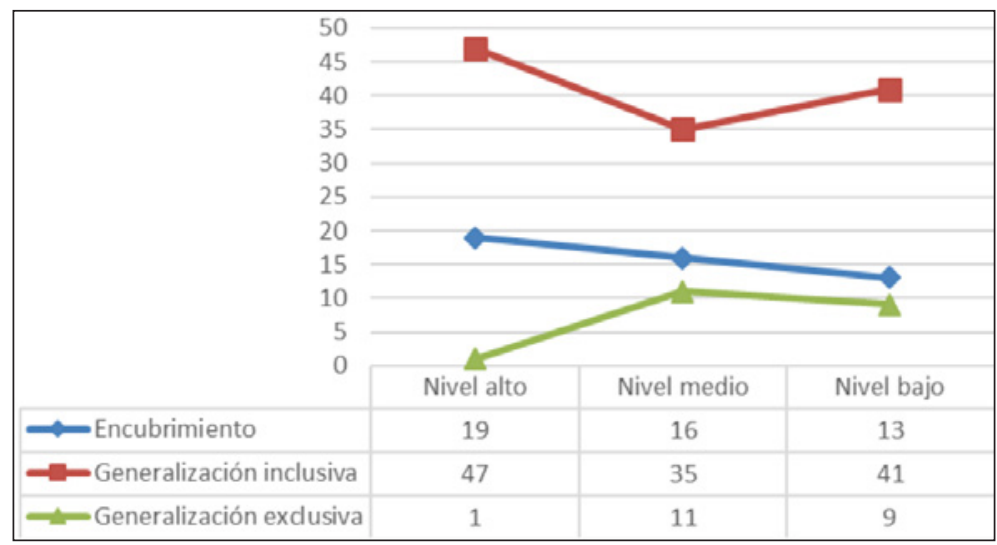

$x^{2}=10,492>9,877 \quad$ g. d. $1.4 \quad p=0,032<0,05^{16}$

Gráfico 8. Lecturas de uno según el nivel de instrucción.

Si desglosamos por tipo de función del indefinido uno, del total de casos $(\mathrm{N}=48)$ de encubrimiento, 39,58\% aparecen en el nivel alto, 33,33\% en el medio y $27,08 \%$ en el nivel bajo. Para la segunda interpretación -generalización inclusiva-, notamos un mayor predominio en el sociolecto alto $(38,21 \%)$ y el bajo $(33,33 \%)$ a diferencia del medio $(28,46 \%)$. En cambio, se percibe la tendencia contraria para los casos en que el hablante establece una generalización de las que se excluye. Así, se ha documentado un $52,38 \%$ en el medio, un $42,86 \%$ en el bajo y tan solo un $4,76 \%$ en el sociolecto alto (se ha localizado un solo ejemplo en el corpus manejado).

\subsection{Criterios estilísticos}

La variable tenor (conocido / no conocido previamente a la entrevista) también ha resultado significativa. En el Gráfico 9, ofrecemos información detallada al respecto:

16. Según la prueba exacta de Fisher, el valor de $p$ es igual a 0,033 . 


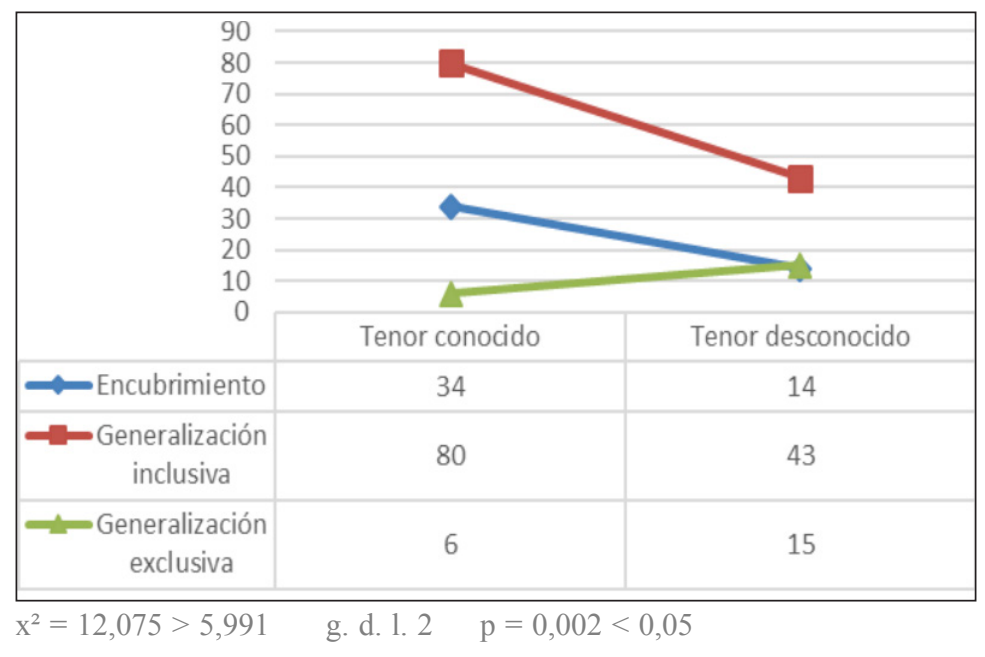

Gráfico 9. Valores de uno y tenor.

Se ha localizado un número mayor de la forma pronominal cuando el tenor es conocido: $62,5 \%$ vs. $37,5 \%$. Según el valor semántico de uno, se observa que el hablante oculta su identidad detrás de sus palabras en un 70,83\% cuando el otro interlocutor es conocido, y un $21,17 \%$ si los dos participantes en la interacción no se conocen previamente. Con respecto a la interpretación generalización inclusiva, del total de 123 casos, se ha documentado un $65,04 \%$ si el tenor es conocido y un $34,96 \%$ cuando es desconocido. En cambio, se manifiesta una tendencia contraria para la lectura generalización exclusiva $(\mathrm{N}=21)$ : uno aparece un $28,57 \%$ cuando los interlocutores se conocen y el $71,43 \%$ si no existe una relación previa entre los participantes en la interacción.

\section{Conclusiones}

En las 72 entrevistas manejadas para este estudio y que forman parte del corpus oral PRESEEA en la comunidad urbana de Sevilla, se ha podido observar que la forma pronominal uno y sus variantes se emplean como un mecanismo de impersonalización con interpretaciones distintas. Por un lado, aparece como generalizador cuya finalidad consiste en persuadir al receptor de la validez de lo expresado por el hablante, sea en los casos en que el hablante se incluye o no en el grupo al que se refiere (inclusivo y exclusivo respectivamente), sea en los que expresa una crítica. Por otro lado, esta forma indefinida actúa como estrategia ocultadora de la identidad del hablante, en busca de acuerdo o aceptación social, 
o como mecanismo de defensa para proteger su imagen. De estas posibles intenciones, es el valor generalizador inclusivo el que más predomina en los materiales analizados.

Así, hemos podido observar que el pronombre uno le permite al hablante encubrir su identidad, minimizar su protagonismo o generalizar, ya que en combinación con distintas clases de verbos sirve para expresar sus creencias y/o pensamientos, su estado físico y psicológico o su participación en diferentes actividades.

Con respecto a la secuencia discursiva, uno se presenta como una estrategia de persuasión. En este caso, el hablante muestra una preferencia hacia la generalización cuando argumenta (intenta convencer al interlocutor de aquello que expresa), pero oculta su identidad cuando relata experiencias personales o ajenas. Asimismo, la presencia de uno es predominante cuando se abordan temas de interés general, que sobrepasan el ámbito privado del hablante, lo que explica su empleo mayoritario con un valor generalizador inclusivo. Cuando se abordan temas que pertenecen a su esfera íntima, se emplea en primer lugar para ocultar su identidad en el discurso, sin embargo, es escasísima la diferencia porcentual con respecto al valor generalizador inclusivo. En cualquier caso, dado que el mecanismo se emplea con menor frecuencia en este ámbito, sería interesante averiguar qué estrategias impersonalizadoras prefiere utilizar el hablante cuando afectan a su vida privada. Para el criterio tenor, se ha encontrado mayor predominio de esta forma cuando los dos hablantes que participan en la interacción se conocen.

Finalmente, aunque en nuestro estudio se pone de manifiesto que el uso del pronombre uno con las interpretaciones identificadas no depende de criterios sociales como el sexo o la edad, hemos podido notar que son la tercera generación y los hombres los que muestran mayor tendencia al empleo de este mecanismo. Según el nivel de instrucción, condicionante que ha resultado significativo, se ha observado un uso mayor de esta forma en el sociolecto alto $(34,89 \%)$ en detrimento del sociolecto medio $(32,29 \%)$ y el bajo $(32,81 \%)$.

A la vista de los resultados obtenidos en este análisis y para tener una visión más amplia del empleo del impersonalizador uno se hace necesario llevar a cabo estudios contrastivos entre la ciudad de Sevilla y otras comunidades de habla de otras variedades del español. Asimismo, sería deseable realizar un estudio comparativo que incluya muestras orales de otras lenguas románicas, como el francés o el rumano, para conocer los mecanismos de impersonalización 
correspondientes al pronombre uno del español, pues hasta donde llegan nuestros conocimientos, todavía no se ha realizado una investigación lingüística contrastiva a gran escala que cuente con estas características.

\section{Bibliografía}

ADAM, J. M. (1992). Les textes : types et prototypes. París: Nathan.

ALCAIDE LARA, E. (2001). "La impersonalidad en los medios de comunicación" en Indagaciones sobre la lengua. Estudios de filología y lingüistica españolas en memoria de Emilio Alarcos. (Eds. E. Méndez, J. Mendoza e Y. Congosto). Sevilla: Universidad de Sevilla: 289-312.

BRIZ GÓMEZ, A. (1998). El español coloquial en la conversación: esbozo de pragmagramática. Barcelona: Ariel.

FERNÁNDEZ, S. (2008). "Generalizaciones y evidencialidad en español”. Revue Romane 43/2: 217-234.

FERNÁNDEZ JUNCAL, C. (2005). Corpus de habla culta de salamanca. Burgos: Fundación Instituto Castellano y Leonés de la Lengua.

FLORES-FERRÁN, N. (2009). "Are you refering to me? The variable use of UNO and YO in the oral discourse". Journal of Pragmatics 4: 1810-1824.

FUENTES RODRÍGUEZ, C. y ALCAIDE LARA, E. (2002). Mecanismos lingüísticos de la persuasión. Madrid: Arco/Libros.

GALLUCCI, M. J y VARGAS, K. (2015). "Estilo directo e indirecto en el Corpus Sociolingüístico de Caracas 1987”. Anuario de Letras 3 (2): 65-103.

GÓMEZ TORREGO, L. (1994). La impersonalidad gramatical: descripción y norma. Madrid: Arco Libros.

GUIRADO, K. (2011). "La alternancia tú-uno impersonal en el habla de Caracas". Lingüistica 26: 26-54.

HAVERKATE, H. (1994). La cortesía verbal. Madrid: Gredos.

HURTADO, L. M. (2012). "La variable expresión de la impersonalidad en el español de los colombianos de Bogotá y Miami” en Linguistic studies in Colombian varieties of spanish. (Eds. R. Orozco y R. File): Madrid/ Frankfurt: Iberoamericana/Vervuert: 141-167.

HURTADO, L. M. y GUTIÉRREZ RIVAS, C. (2016). “La versatilidad del pronombre uno para expresar posicionamiento frente a lo enunciado en el español de Barranquilla. Colombia". Forma y función 29: 37-60.

JESPERSEN, O. (1975). La filosofia de la gramática. Barcelona: Anagrama.

KLUGE, B. (2010). "El uso de formas de tratamiento en las estrategias de generalización" en Formas y fórmulas de tratamiento en el mundo hispánico. 
(Eds. M. Hummel, B. Kluge y M. E. Vázquez). México: El Colegio de México: 1108-1136.

LEÓN-CASTRO GÓMEZ, M. (2012). Desfocalización y refocalización del centro deíctico personal: perspectivas sintácticas, pragmáticas y textuales. Tesis doctoral. <http://fondosdigitales.us.es/tesis/tesis/1877/desfocalizaciony-refocalizacion-del-centro-deictico-personal-perspectivas-sintacticaspragmaticas-y-textuales/>.

LEÓN-CASTRO GÓMEZ, M. (2015). "Variación en la segunda persona del singular como estrategia de indeterminación referencial en el habla de Sevilla: sociolecto bajo" en La variación en el Español actual. Estudios dedicados al profesor Pedro Carbonero. (Eds. M. León-Castro Gómez y A. Zerva). Sevilla: Servicio de Publicaciones de la Universidad de Sevilla: 211-232.

LEÓN-CASTRO, M. y REPEDE, D. (2018). "El pronombre indefinido uno como estrategia de impersonalización: un estudio en el corpus oral PRESEEASevilla”. Nueva Revista del Pacífico 69: 67-89.

LORENZO, E. (1984). "Novedades sobre la segunda persona y la expresión impersonal" en ATHLON, Satura Grammatica in honorem Francisci $R$. Adrados. (Ed. Luis Alberto de Cuenca). Madrid: Gredos: 279-286.

MANCERA RUEDA, A. (2009). Oralidad de la prensa escrita. Bern: Peter Lang.

MARTÍNEZ RIPOLL, D. (1999). “¿Es lat. alt(e)rum el étimo de esp. otro?” en Homenaje al profesor Trigueros Cano. (Eds. P. L. Ladrón de Guevara et al.). Murcia: Universidad de Murcia: 487-518.

MORALES DE WALTERS, A. (1992). "Se y uno como formas impersonales: Reanálisis de la cuestión”. Voz y Letra: Revista de Filología 3 (1): 101-109.

MORALES DE WALTERS, A. (1995). "The loss of the Spanish impersonal particle se among bilinguals: A descriptive profile" en Spanish in the four continents: studies in language contact and bilingualism. (Ed. C. SilvaCorvalán). Washington D.C.: Georgetown University Press: 148-162.

MUÑIZ CACHÓN, C. (1998). Impersonalización y despersonalización. Estudio contrastivo. Oviedo: Publicaciones del Departamento de Filología Española. POSIO, P. (2017). "Entre lo impersonal y lo individual. Estrategias de impersonalización individualizadoras en el español y portugués europeos". Spanish in Context 14 (2): 209-229.

REAL ACADEMIA ESPAÑOLA Y ASOCIACIÓN DE ACADEMIAS DE LA LENGUA ESPAÑOLA (2009). Nueva gramática de la lengua española. Madrid: Espasa. 
RAE (2014). Diccionario de la lengua española. <http://dle.rae.es/?id= b6hEWeB|b6iKApr>. (Acceso octubre de 2018).

RIDRUEJO, E. (1981). "Uno en construcciones genéricas". Revista de Filología Española 61 (1-4): 65-83.

RIEGEL, M., PELLAT, J.-C. y RIOUL, R. (1994). Grammaire méthodique du français. Paris : Presses Universitaires de France.

SINNER, C. (2004). El castellano de Cataluña. Estudio empirico de aspectos léxicos, morfosintácticos, pragmáticos y metalingüisticos. Tubinga: Max Niemeyer Verlag. 